\title{
KOLONIALISME DAN IDENTITAS KEBANGSAAN NEGARA-NEGARA ASIA TENGGARA
}

\author{
Heri Susanto \\ Program Studi Pendidikan Sejarah FKIP Universitas Lambung Mangkurat Banjarmasin
}

\begin{abstract}
Abstrak. Nasionalisme dapat dikategorikan menjadi civic nationalism dan ethnic nationalism. Ethnic nationalism didefinisikan dalam konteks etnis dan keturunan dari generasi sebelumnya. Hal ini juga mencakup gagasan budaya bersama antara anggota kelompok, dan biasanya juga mencakup bahasa yang sama. Sedangkan, civic nationalism adalah bentuk nasionalisme yang berasal dari legitimasi politik dari keikutsertaan aktif masyarakat, yang mana hal tersebut merupakan "the will of people". Ethnic nationalism misalnya ditunjukkan oleh Thailand, sedangkan civic nationalism misalnya ditunjukkan oleh Philipina dan Indonesia. Dalam tinjauan ini Malaysia dapat dikatakan mengalami kedua tipe identifikasi ini, ditengah upaya mengukuhkan identitas ke-Melayu-an, Malaysia juga harus mampu mengakoomodir keinginan warga negara lain non Melayu. Meskipun demikian, bila dilihat dari sisi identitas nasional nation state, maka Indonesia dapat dikatakan satusatunya negara di Asia Tenggara yang secara tegas menggunakan terminologi multikultural dalam penamaan negara. Ditinjau dari sejarah kawasan sangat jelas bahwa nasionalisme Indonesia tidak dibangun atas dasar budaya majemuk, akan tetapi keinginan bersama yang disebut civic nationalism murni.
\end{abstract}

Kata-kata kunci: kolonialisme, nasionalisme, identitas kebangsaan, Asia Tenggara

\begin{abstract}
Nationalism could be categorized by civic nationalism and ethnic nationalism. Ethnic nationalism is defined in the ethnical and descendant context. This will also cover the idea of collective culture between a member of group and commonly consists of the same language. Civiv nationalism is a form of nationalism derived from the political legitimation of social participation, as called the will of people. Ethnic nationalism, for example, is showed by Thailand and civic nationalism is represented by Philipina and Indonesia. This study places Malaysia as both nationalism. They accommodate the non-Malay citizens in the term of nation-state. Indonesia could be one of Southeast Asian countries using a multicultral perspective in naming a state. Based on the area history, Indonesian nationalisms are not shaped by multiculture, but the will to live together or the pure civic nationalism.
\end{abstract}

Keywords: colonialism, nationalism, national identity Southeast Asia

Nasionalisme adalah satu paham yang menciptakan dan mempertahankan kedaulatan sebuah negara (nation) dengan mewujudkan satu konsep identitas bersama untuk sekelompok manusia. Nasionalisme tiap bangsa di dunia tercipta melalui proses yang berbeda-beda, sehingga pada saat nasionalisme tersebut menampakkan wujudnya juga mempunyai bentuk dan ciri yang berbeda. Bangsabangsa di kawasan Asia Tenggara, pada umumnya mengalami proses pembentukan identitas kebangsaan setelah melalui proses yang panjang dalam pergulatan politik pada pertengahan abbad ke-20. Tumbuhnya nasionalisme ini dapat dikatakan merupakan dampak positif [baca: dipicu] dari praktik kolonialisme.

Nasionalisme pada abad ke-20 dianggap sebagai senjata terkuat dalam politik internasional (Barrington, t.t). Akan tetapi, sampai saat ini pengertian nasionalisme sendiri sering dihadapkan pada perdebatan mengenai apa arti sebenarnya dari nasionalisme. Menurut Anderson (2008), nasionalisme berasal dari kata "nation" yakni komunitas orang-orang yang terikat oleh rasa kebersamaan dan percaya untuk berbagi baik warisan masa lalu atau takdir untuk masa depan. Dari sudut pandang lain istilah "nasionalisme" seringkali digunakan untuk menggambarkan dua fenomena; yang per- 
tama adalah sikap kepedulian suatu bangsa terhadap identitas nasionalnya, dan yang kedua sebagai tindakan suatu bangsa ketika mencari cara untuk mencapai atau mempertahankan nasibnya sendiri (self-determination) (Kellas, 1998). Menurut Emerson (1946) menginterpretasikan nasionalisme sebagai sebuah fenomena yang terkait dengan gagasan yang diwakili oleh kemampuan manusia untuk mengubah dan mengontrol aspek sosial dan materiil dimana ia tinggal. Berbeda halnya dengan John Plamenatz (1973) yang menyebutkan bahwa "nationalism is the desire to preserve or enhance a people's national or cultural identity when that identity is threatened, or the desire to transform or even create it where it is felt to be inadequate or lacking". Dengan demikian menurut Plamenatz secara nasionalisme cenderung muncul ketika warga bangsa sadar dan kritis akan perubahan dan keragaman budaya.

Nasionalisme merupakan tali pengikat yang kuat, yakni paham yang menyatakan bahwa kesetiaan individu harus diserahkan kepada negara kebangsaan, sebagai ikatan yang erat terhadap tumpah darahnya. Keinginan untuk bersatu, persamaan nasib akan melahirkan rasa nasionalitas yang berdampak pada munculnya kepercayaan diri, rasa yang amat diperlukan untuk mempertahankan diri dalam perjuangan menempuh suatu keadaan yang lebih baik. Dua faktor penyebab munculnya nasionalisme, yaitu faktor intern dan ekstern. Faktor pertama sebagai bentuk ketidakpuasan terhadap penjajah yang menimbulkan perlawanan rakyat dalam bentuk pemberontakan atau peperangan. Sedang faktor kedua sebagai renaissance yang dianggap simbol kepercayaan atas kemampuan diri sendiri (Perdanayudha, 2010).

Sejalan dengan kenyataan tersebut kita dapat memahami bahwa nasionalisme suatu bangsa dapat terbentuk apabila terdapat kriteria pengikat yang kuat seperti dijelaskan oleh Hobsbawm(1990:5); "attempts to establish objective criteria for nationhood, or to explain why cer- tain grouphs have become 'nations' and others not, have often been made, based on single criteria such as language or ethnicity or a combination of criteria such as language, common territory, common history, cultural traits or whatever else".

Terminologi Hobsbawm tentang kriteria pengikat ini memberikan arti bahwa untuk memiliki nasionalisme atau proses pembentukan nasionalisme akan selalu didahului oleh proses penciptaan, penemuan atau pemahaman identitas atau faktor-faktor lain yang dapat menjadi pengikat suatu bangsa. Dengan demikian dapat pula dikatakan bahwa untuk memiliki nasionalisme yang kuat, warga suatu bangsa harus memiliki pertalian dalam hal tertentu yang menjelaskan identitas mereka secara bersama sebagai sebuah nation.

\section{ETNISITAS, IDENTITAS, DAN NASIONAL- ISME BANGSA-BANGSA ASIA TENGGARA}

Menurut tinjauan King dan Wilder (2012) pembentukan identitas nation bagi negara-negara di kawasan Asia Tenggara, utamanya Indonesia di awali dengan proses penyatuan atau rekonsiliasi etnik. Etnisitas dalam pandangan King dan Wilder bukan hanya dipremiskan pada kekekalan diri biologis namun juga pada keanggotaan bidang interaksi dan komunikasi bersama berdasarkan pada nilai-nilai dan perilaku bersama. Proses ini terjadi dengan pola yang berbeda-beda pada tiang bangsa di Asia Tenggara. Proses penyatuan ini menurut Anderson (2008:8) diawali dari adanya perasaan/bayangan bersama sebagai sebuah bangsa. Bayangan tentang kebersamaan inilah yang kemudian mewujudkan semangat nasionalisme. Nasionalisme merupakan salah satu unsur dalam pembinaan kebangsaan atau nation-building. Dalam proses pembinaan kebangsaan semua anggota masyarakat bangsa dibentuk agar berwawasan kebangsaan serta berpola tatalaku secara khas yang mencerminkan budaya maupun ideologi. Proses pembinaan kebangsaan memang unik bagi tiap bangsa. Bagi masyarakat bangsa yang plural akan tetapi homogen, seperti Amerika Serikat, konsep 
melting-pot dapat diterapkan. Namun bagi masyarakat Indonesia yang plural dan heterogen akan lebih mengedepankan wawasan kebangsaan yang unsur-unsurnya adalah rasa kebangsaan, faham kebangsaan, dan semangat kebangsaan atau nasionalisme (Edi Sudrajat, 1998), dalam keadaan ini diperlukan nasionalisme yang toleran. Nasionalisme yang toleran adalah nasionalisme yang identitas nasionalnya diupayakan untuk bisa merasuk kedalam kehidupan pribadi dan kebudayaan, bukan dipolitisasi dan dijadikan hak dasar hukum untuk memaksa(Diamond, 1998).

Hakikat Indonesia adalah suatu cita-cita politik untuk mempersatukan unsur-unsur tradisi dan inovasi serta keragaman etnis, agama, budaya, dan kelas sosial ke dalam suatu "botol baru" bernama "negara-bangsa". Hasrat persatuan itu memang terjadi secara negatif, didorong oleh kehendak menghadapi musuh bersama (negara kolonial), dan secara positif, tercipta oleh hasrat untuk mencapai kebahagiaan bersama (Yudi, 2011:357).

Konsep bangsa yang telah dimiliki masyarakat sampai saat ini pada dasarnya merupakan penerusan dari konsep bangsa menurut faham nasionalisme dari pendiri bangsa. Visi nasionalisme Indonesia pada masa pergerakan nasional dan perjuangan kemerdekaan secara jelas dirumuskan oleh pendiri bangsa sebagai orientasi pemikiran perjuangan untuk mewujudkan kemerdekaan Indonesia dari belenggu penjajahan Belanda dengan mendirikan negara kesatuan, baik kesatuan tanah air, bangsa, maupun bahasa dan kebudayaannya. Karena itu ciri dan jiwa nasionalisme pada masa pergerakan adalah sifat anti kolonial dan semangat untuk membangun persatuan dan kesatuan masyarakat tanah jajahannya dari kemajemukannya menjadi kesatuan bangsa motto Bhineka Tunggal Ika dari masa Majapahit diangkat sebagai semboyan dalam upaya untuk mewujudkan terciptanya bangunan bangsa yang dicita-citakan (Djoko Suryo, 2003:5).

Soetjipto Wirosarjono (1998) menjelaskan bahwa kesadaran dan semangat nasionalisme yang tumbuh dan berkembang di Indonesia berlatar belakang kolonialisme. Suku-suku bangsa yang ada di Indonesia disatukan oleh pengalaman yang sama tatkala sama-sama dijajah oleh bangsa Belanda. Tatkala Indonesia berdiri, suku-suku bangsa itu kemudian menjadi bagian dari bangsa dan negara Indonesia. Maka semua suku bangsa (daerah) yang ada di Nusantara itu disatukan oleh nasib dan perjuangan yang sama untuk melawan penjajahan.

Nasionalisme merupakan jawaban dari tirani bangsa asing atas kehidupan masyarakat pada abad ke - 19 sampai dengan awal abad ke - 20 . Dalam bukunya Robert Edward Elson menyebutkan bahwa pertumbuhan identitas pribumi di Hindia, dirangsang walau bukan diciptakan oleh imperialisme Belanda (Elson, 2008:12). Pendapat ini bukan tanpa alasan, karena dalam fakta sejarah sebelum kedatangan dan kemudian penguasaan bangsa asing, terutama Belanda, Nusantara kita adalah kumpulan kepulauan yang didalamnya terdapat banyak negara-negara tradisional yang berdiri sendiri, bahkan cenderung saling bermusuhan.

Sebuah contoh ekstrem mengenai proses penciptaan sebuah bangsa di Asia Tenggara ini adalah Laos, masyarakat Laos dataran rendah membentuk sebuah sebuah kelompok etnis terpisah yang menunjukkan kebangsaan Laos. Fakta sejarah memperlihatkan bahwa negara Laos modern hanya ada karena proses pendudukan kolonial Perancis. Tanpa peran Perancis hampir bisa dipastikan bahwa daerah dataran rendah Laos akan menjadi bagian dari negara Thailand(King \& Wilder, 2012). Pendudukan Perancis telah menjadi jalan bagi masyarakat Laos untuk membentuk identitas bersama sebagai suatu bangsa yang merdeka.

Sementara itu di Malaysia etnisitas menjadi semakin berkaitan dengan identitas politik, di mana orang-orang Melayu, Cina dan India masingmasing membentuk partai-partai berbasis etnis atau komunal mereka sendiri. Perbedaan antar kelompok ini ditunjukkan dalam kaitannya dengan 
ketidakseimbangan ekonomi, khususnya antara orang Cina dan Melayu, dalam kaitannya dengan hak-hak istimewa orang Melayu pribumi dalam pekerjaan sektor publik, pendidikan dan bidang ekonomi umum (Lee dalam King \& Wilder, 2012). Nagata (1979) dalam tinjauannya menguraikan jawaban tentang bagaimana identitas kebangsaan Malaysia terbentuk; 1) asimilasi pada keMalaysia-an; 2) penciptaan budaya nasional Malaysia dengan mengakomodir elemen-elemen kelompok etnis yang ada; 3) setting pluralistik di mana komunitas-komunitas utama menjaga keunikan kultural mereka; 4) asimilasi pada sebuah kebudayaan netral yang diwesternisasi melampaui identitas individual.

Beberapa contoh pembentukan identitas kebangsaan tersebut memperlihatkan bahwa pandangan Hobsbawm yang menyatakan bahwa selalu ada semacam kriteria pengikat suatu kelompok masyarakat untuk menjadi bangsa. Kriteria tersebut dapat berupa aktor alamiah atau sebuah kondisi yang terjadi dalam proses sejarah, maupun setting yang sengaja diciptakan untuk dipahami dan diikuti oleh masyarakat suatu bangsa sehingga mereka dapat merumuskan cita-cita bersama sebagai sebuah bangsa.

\section{SIKAP ANTI KOLONIALISME DAN AWAL KESADARAN BERBANGSA DI KAWASAN ASIA TENGGARA}

Secara umum pola nasionalisme di kawasan Asia Tenggara adalah reaksi untuk mengusir penjajah dari tanah mereka, akan tetapi adanya perbedaan corak politik dan faktor-faktor intern tiap wilayah menyebabkan tidak mudah untuk membuat generalisasi proses lahirnya nasionalisme negara-negara Asia Tenggara dengan tepat. Terlebih dalam konteks sejarah kawasan tidaklah adil apabila kita mengesampingkan keunikan dan perjalanan historis masing-masing negara tersebut. Untuk dapat membuat perbandingan yang lebih jelas, maka perlu dilihat perkembangan nasionalisme dan pembentukan nation state di negara-negara kawasan Asia Tenggara.

\section{Philipina}

Perjalanan nasionalisme Philipina tergolong nasionalisme tertua di Asia Tenggara dalam proses menentang penjajahan. Hal ini disebabkan karena Philipina mendapat pendidikan modern tertua di luar Eropa. Pendidikan tersebut diselenggarakan oleh Ordo Yesuit yang berkarya di Philipina. Karya Ordo tersebut dilindungi oleh pemerintah Spanyol sebab dinilai turut mengkonsolidasi kekuasaan pemerintah. Gerakan nasional yang pertama di Philipina adalah Liga Philipina yang berdiri tahun 1880 dipimpin oleh Jose Rizal. Perjuangan Rizal melawan pemerintah Spanyol dipropagandakan lewat dua novelnya yakni Noli me Tangere dan El Filibusterisme.

Sekitar tahun 1890-an gerakan nasional Philipina mulai menunjukkan sifat-sifat radikal. Gerakan yang bersifat radikal tersebut berlanjut ke pergolakanpergolakan. Selama penjajahan Spanyol (1571-1898) ada sekitar 100 pergolakan melawan pemerintah kolonial itu (Lightfoot, 1973: 92). Sejak tahun 1897, dibawah pimpinan Emmilio Aquinaldo salah satu gerakan yang paling keras yaitu Katipunan berubah menjadi gerakan yang sangat nasionalis. Katipunan berarti persekutuan tertinggi dan yang paling dihormati di antara putera-putera negeri. Aquinaldo membantu Amerika Serikat menumbangkan pemerintah Spanyol di Philipina (1898) dan memproklamasikan kemerdekaan Philipina pada tanggal 12 Juni 1898. Namun Amerika Serikat tidak mengakui kemerdekaan Philipina itu tetapi justru menghancurkannya. Dari peristiwa itu kemudian diketahui motif sebenarnya Amerika adalah untuk mengambil alih kekuasaan di Philipina, bukan membebaskan negara itu dari penajahan.

Berada dibawah penajahan Amerika, kaum nasionalis Philipina mengubah strategi perjuangan. Jalur perjuangan diplomasi dilakukan dengan mendirikan partai sebagai wadah perjuangan. Tahun 1907 didirikan Partindo Nacionlista (Partai Nasionalis) dengan pimpinan Sergio Osmena, Manuel Quezon dan Manuel Roxas. Partai tersebut 
menjadi lembaga politik yang besar dan bersifat kompromistis. Dampak positifnya adalah diberi kemudahan legislatif dan pelayanan sipil.

Kurun waktu 1920an teradi krisis pergerakan setelah Amerika berusaha menghambat emansipasi, berbagai usaha dilakukan kaum nasionalis antara lain melalui usaha mempengaruhi publik lewat seni, pertunjukan dan upaya diplomasi langsung kepada pemerintah Amerika agar memberikan kemerdekaan kepada Philipina. Osmena dan Roxas pada tahun 1930-an ke Amerika, untuk mendapat dukungan dan upaya tersebut didukung oleh tokoh-tokoh Amerika yang mempunyai kepentingan ekonomi. Sebagai tindaklanjut pada tahun 1932 dibuat RUU Hare Haves Cutting yang menyatakan bahwa setelah 10 tahun menjalani masa peralihan, maka Philipina akan dimerdekakan.

Undang-undang kemerdekaan Philipina tersebut ditolak oleh Quezon dengan alasan adanya syarat kemudahan militer Amerika Serikat setelah merdeka berlawanan dengan harga diri bangsa Philipina. Tahun 1934 Quezon menyempurnakan RUU sebelumnya dengan eda kemerdekaan Philipina 12 tahun kemudian, perubahan itu mendongkrak nama Quezon yang akhirnya membawa dirinya menjadi presiden pertama pemerintah otonomi tahun 1935. Pada masa peralihan itu meletuslah Perang Dunia II, dan Philipina jatuh ke tangan Jepang. Akan tetapi para pemimpin Philipina tetap setia kepada Amerika sehingga membantu Amerika melawan Jepang. Setelah Jepang menyerah, Amerika kembali ke Philipina, dan menepati janjinya yakni memberi kemerdekaan Philipina pada tanggal 4 Juli 1946 dengan menjadikan Roxas sebagai presidennya.

\section{Myanmar}

Gerakan nasional Myanmar dimulai pada tahun 1906 yang ditandai dengan pembentukan YMBA (Young Man Budhis Asociation) atau Persatuan Pemuda Birma. Mula-mula organisasi tersebut bergerak dalam bidang agama dan sosial sehingga belum bercorak politik, tetapi lebih banyak bergerak dalam bidang pendidikan (Donison, 1970: 102).

Perkembangan nasionalisme Myanmar mulai kelihatan setelah Perang Dunia I, terutama setelah Inggris memisahkan Myanmar dari konstitusi India (Inggris). PD I cukup mengguncangkan Myanmar dan segera mendorong lahirnya kesadaran politik yang lebih nasionalistis. Hal ini ditandai dengan berlangsungnya pemogokan di universitas, dan kemudian dilanjutkan dengan perubahan YMBA menjadi GCBA (Dewan Umum Persatuan Burma) pada tahun 1921, yang merupakan organisasi politik nasionalis yang luas. Setelah gerakan nasional Burma menunjukkan tujuan politik yang jelas, maka Inggris mengubah haluan politik kolonialnya. Tahun 1923 Inggris memperkenalkan sistem Dyarchy seperti yang diterapkan di provinsi di India. Usaha Inggris itu dapat memecah GCBA dalam dua partai yaitu Partai Dua Puluh Satu yang puas dengan perubahan itu dan bersedia duduk dalam dewan perundangundangan serta Partai U Chit Hlaing yang membela prinsip non-koperasi dan ingin berjuang untuk memperoleh konsesi baru. Dalam perkembangannya, maka muncullah tokoh-tokoh nasionalisme Myanmar seperti DR Ba Maw dari Partai Sinyetha, U Ba Pe dari Partai Dua Puluh Satu, dan U Saw dari Partai U Chit Hlaing, kemudian muncul pula Thakin Nu dan U Aung San dari Partai Thakin (Donison, 1970: 117).

Tahun 1930an Komisi Simon mengajukan ide untuk pemisahan Myanmar dari India. Pada awalnya ide pemisahan tersebut berasal dari kaum nasionalis, akan tetapi kemudian kaum nasionalis mencurigai bahwa Inggris akan mengambilalih Myanmar setelah India lepas dari Inggris. Karena pertimbangan tersebut, kemudian kaum nasionalis mendirikan liga anti pemisahan. Kaum nasionalis berupaya untuk mempengaruhi publik Myanmar dan pada akhirnya berhasil memperoleh dukungan publik setelah diadakan pemungutan suara. Peristiwa tersebut membuat Inggris marah dan memutuskan untuk mengadakan memorandum guna memilih untuk tetap bersatu dengan India atau 
memisahkan diri dan menolak usul kaum nasionalis untuk menyutujui memasukkan Myanmar dalam federasi India dengan hak mengundurkan diri. Pemisahan pun terjadi pada tahun 1935.

Pada tahun 1935 lahir organisasi Dobama Asiayone (Kami Masyarakat Burma). Gerakan ini diilhami paham sosialis dan ajaran komunis, serta terpengaruh modernisasi Jepang (Koen, 1956: 223). Karena para anggotanya saling menyebut thakin (tuan), maka partai itu juga disebut partai Thakin. Tujuan penyebutan itu adalah agar Inggris juga menyebut thakin kepada para anggota partai itu, misalnya Thakin Nu, Thakin U Aung San, dan lain-lain. Dengan demikian secara tidak langsung Inggris mengakui kedudukan yang sama dengan orang-orang Myanmar. Partai Thakin bersifat revolusioner, tuntutannya bersifat radikal karena mereka menuntut kemerdekaan penuh bagi Myanmar. Untuk mencapai tujuannya itu, partai Thakin bersedia menerima bantuan dari manapun datangnya (Wiyono, 1982: 10).

Taktik perjuangan partai Thakin adalah membangkitkan semangat nasionalisme rakyat dengan mengorganisir petani, buruh dan gerakan pemuda. Dengan meningkatnya agitasi partai Thakin maka menjadi semakin besar gerakan menentang Inggris dan secara tidak langsung menjadi penyebab jatuhnya kabinet pertama saat itu. Saat itu sesungguhnya nasionalisme Myanmar berada di simpang jalan antara kelompok nasionalis moderat yang berkuasa dengan kelompok nasionalis radikal yang mencoba mencari dukungan rakyat guna merebut kepemimpinan dari tangan politisi yang lebih tua. Akhirnya generasi muda pimpinan U Aung San berhasil merebut kepemimpinan pergerakan di Myanmar. Setelah Perang Dunia II Inggris kembali ke Myanmar. Gerakan politik Myanmar yang dipimpin U Aung San diajak berunding tentang kemerdekaan Myanmar. Pada saat sidang mempersiapkan kemerdekaan Myanmar, tiba-tiba segerombolan orang bersenjata masuk dan membunuh U Aung San. Ternyata gerombolan tersebut atas suruhan U Saw, sehingga U Saw akhirnya dihukum mati. U Aung San di- ganti $\mathrm{U} \mathrm{Nu}$ dan pada tanggal 4 Januari 1948 kemerdekaan Myanmar diproklamasikan.

\section{Indocina}

Seperti pada umumnya daerah-daerah lain di Asia Tenggara, nasionalisme di Indocina dipelopori oleh kaum intelektual yang telah mengenyam pendidikan Barat. Gerakan nasional di Indocina dipelopori oleh bangsa Vietnam, sebab penduduknya paling besar dan punya nasionalisme tradisional (kebiasaan mengusir penjajah dari Cina).

Gerakan nasional yang tertua di Vietnam adalah Vietnam Restoration League (1907) yang didirikan oleh Cong De. Kemudian disusul berdirinya Vietnam Quak Dan Dang yang dalam perkembangannya memimpin pemberontakan kaum nasionalis tahun 1930. Keduanya gerakan non-komunis yang sering terlibat konflik intern. Konflik-konflik itu banyak makan korban, sehingga kurang menarik hati rakyat. Para pemimpinnya cenderung akan menjadikan Vietnam sebuah negara model Barat.

Akibat pemberontakannya tahun 1930, gerakan nasionalisme Vietnam ditindas dengan kejam oleh Prancis. Sisa-sisa gerakan tersebut tinggal kelompok-kelompok komunis yang militant. Pada tahun 1930 itu pula Nguyen Ai Quoc mengumpulkan kelompok-kelompok komunis itu dan dibentuk menjadi Partai Komunis Indocina(Sardiman, 1983: 11). Nguyen Ai Quoc lalu berganti nama Ho Chi Minh (pencari kecerahan). Sedangkan nama kecilnya adalah Nguyen Tat Tanh dan lahir di Kim Lien, tanggal 19 Mei 1890. Seperti pemimpinpemimpin pergerakan nasional di Indocina sebelumnya, maka Ho Chi Minh termasuk pemimpin nasionalis yang mengenyam pendidikan Barat. Dengan demikian jelaslah bahwa nasionalisme Vietnam tumbuh dan berkembang setelah Prancis mendirikan sekolah-sekolah di Vietnam (Karnow, 1975: 97).

Ho Chi Minh menjadikan teman-temannya sebagai tangan kanan. Kebanyakan dari mereka pernah dipenjarakan oleh Perancis. Gerakan ini berkembang pesat karena didukung oleh kondisi 
sosial ekonomi yaitu propaganda untuk mengentaskan rakyat dari kemiskinan. Pasca Perang Dunia II berakhir, Ho Chi Minh memproklamasikan kemerdekaan Vietnam pada tanggal 2 September 1945 dengan wilayah hanya meliputi Vietnam Utara, sedangkan Vietnam Selatan diduduki Prancis. Karena itu Republik Vietnam pimpinan Ho Chi Minh disebut Vietnam Utara sedangkan Vietnam Selatan dijadikan negara boneka Prancis.

Pasca proklamasi perang Vietnam dengan Perancis masih terus berkobar. Pada pertempuran di Dien Bien Phu tahun 1953, Prancis menderita kekalahan besar dan membawa masalah Vietnam ke Perjanjian Jenewa pada tahun 1954. Hasil perjanjian tersebut mengakui lahirnya negara-negara nasional di Indocina, yaitu Vietnam Utara, Vietnam Selatan, Laos dan Kamboja sebagai negara yang merdeka penuh. Di sisi lain, hasil perjanjian itu memberi peluang bagi Vietnam Utara untuk menguasai Vietnam Selatan. Dengan bantuan Rusia dan Cina, Vietnam Utara terus menekan Vietnam Selatan yang didukung Amerika Serikat. Akhirnya Amerika Serikat mengundurkan diri dari Vietnam Selatan sehingga dengan mudah Vietnam Utara mencaplok Vietnam Selatan pada tahun 1975. Sejak itu Indocina hanya terdiri dari negaranegara Vietnam, Laos dan Kamboja yang kesemuanya berpaham komunis.

\section{Malaysia, Singapura, dan Brunei Darussalam}

Masalah utama dalam upaya konsolidasi nasional Malaysia adalah adanya perbedaan tiga etnis utama, yaitu Melayu, Cina dan India. Modernisasi yang dihembuskan oleh pemerintah kolonial Inggris terhadap Malaya diterima secara tidak merata oleh ketiga etnis penghuni jazirah Melayu. Kecenderungan elite intelektual yang ingin mengadakan modernisasi di antara ketiga etnis besar (Melayu, Cina, dan India), terutama difokuskan ke masyarakatnya sendiri. Nasionalisme orang Cina dan India dikaitkan dengan perkembangan politik di India dan di Cina. Orang Melayu setia kepada kerajaan-kerajaan Melayu, mereka menentang kedudukan imigran Asia terutama Cina, bahkan kurang mempedulikan daerahnya yang diduduki Inggris.

Pemerintah kolonial Inggris bisa memahami dengan cermat susunan masyarakat feodal di Malaya. Inggris mengerti bahwa orang-orang Melayu lebih membenci orang-orang Cina dari pada Inggris. Ada ketakutan dikalangan orang-orang Melayu jika kemudian hari orang Cina dan India menguasai mereka. Karena itu Inggris terus berusaha melindungi posisi orang Melayu dengan cara memberikan posisi khusus pada mereka. Posisi khusus orang-orang Melayu itu memberikan kesan bahwa satu-satunya yang mampu menjamin atau melestarikan masyarakat Melayu hanyalah Inggris, dan perlindungan seperti itu cukup untuk mencegah orang-orang Melayu memberontak pemerintah kolonial Inggris. Sementara itu usaha Inggris memberi kondisi dan kesempatan kepada pembangunan ekonomi secara besar-besaran membuat orang Cinapun tetap tidak menentang kekuasaan Inggris. Keberatan mereka adalah masalah diskriminasi terhadap hak khusus dan pernyataan orang Melayu bahwa Malaya adalah sebuah negeri Melayu. Persimpangan jalan perkembangan nasionalisme Malaya tidak hanya diwarnai oleh perbedaan etnis, tetapi di kalangan orang-orang Melayu sendiri terdapat perbedaan konsep hari depan Malaya.

Perbedaan konsep ini mencakup identitas bangsa Melayu dan jalan politik yang harus mereka pilih di masa depan. Pada umumnya para Sultan merasa lebih aman di bawah Inggris sebab mereka khawatir kalau setelah Malaya merdeka akan kehilangan kekuasaaannya. Tokoh lain seperti Jacob Ibrahim, berkeinginan agar jajahan Belanda (Indonesia) dengan jajahan Inggris (Malaya) dikemudian hari dijadikan satu menjadi Indonesia Raya dan Melayu Raya sehingga bangsa Melayu akan menjadi bangsa yang besar di Asia Tenggara. Sedangkan Datuk Onn bin Jaafar ingin membentuk Negara Malaya yang mencakup ketiga etnis dengan Melayu sebagai pemegang kekuasaan politik. 
Berbeda dengan beberapa kawasan di Asia Tenggara, di Malaya Perang Dunia II tidak membawa dampak yang begitu berarti. Itulah sebabnya, Malaya tergolong lambat perkembangannya nasionalismenya. Di bawah pimpinan Tengku Abdul Rahman, Malaya pada tanggal 31 Agustus 1957 memperoleh kemerdekaannya.

Sementara itu Singapura dan Brunei Darussalam juga bekas rumpun jajahan Inggris di Malaya. Akan tetapi pada saat Malaya merdeka tanggal 31 Agustus 1957 sebagai PTM (Persekutuan Tanah Melayu), Singapura dan Brunei tidak ikut merdeka. Setelah PTM berkembang menjadi Malaysia pada 16 Sepetember 1963, Singapura bergabung dengan Malaysia tetapi Brunei tetap menjadi protektorat Inggris. Pada awalnya tokoh Singapura berpendapat apabila mereka berdiri sendiri sebagai negara pulau kecil yang terletak di daerah yang strategis, maka akan merasa sulit untuk mempertahankan diri. Setelah masalah ras semakin memanas di Malaysia, di mana ras Cina banyak dibatasi, maka Singapura yang mayoritasnya Cina merasa terancam. Pada tanggal 9 Agustus 1965 Singapura di bawah Perdana Menteri Lee Kuan Yew memisahkan diri dari Malaysia, dan Singapura berdiri sendiri sebagai negara republik. Sementara itu raja Brunei yang ditolak oleh Malaysia untuk menjadi Raja Malaysia, akhirnya tidak mau bergabung dengan Malaysia. Setelah melalui berbagai perundingan dengan Inggris, pada tanggal 1 Januari 1984 Brunei memproklamasikan kemerdekaannya. Gerakan nasional di Singapura dan Brunei memang tidak sehebat di Indonesia maupun di Vietnam, namun proses nasionalisme tetap ada, yang akhirnya terwujud sebagai negara nasional Singapura dan Brunei Darussalam.

\section{Thailand}

Gerakan nasionalisme yang dilancarkan oleh raja dan para bangsawan, bertujuan untuk mempertahankan kemerdekaan negeri itu dari ancaman bangsa Barat. Nasionalisme Thailand terwujud dalam diplomasi dan modernisasi. Nasionalisme Thailand tidak bertujuan mengusir penjajah untuk membentuk negara merdeka, melainkan mempertahankan kemerdekaan dengan jalan memajukan bangsa lewat diplomasi dan modernisasi. Politik diplomasi Thailand adalah berusaha agar jangan sampai kebijakan Thailand dapat dijadikan alasan bagi bangsa-bangsa Barat untuk menyerang Thailand. Di samping membina hubungan baik dengan Inggris, Thailand juga membina hubungan baik dengan Amerika Serikat, Denmark (1858), Belanda (1860), dan Prusia (Jerman). Langkah tersebut terbukti sangat efektif membentuk image Thailand sebagai negara yang bersahabat dengan Barat.

Selain Inggris, bangsa Barat yang paling berbahaya bagi kemerdekaan Thailand adalah Prancis. Untuk mencegah ancaman Prancis, raja Thailand menghapus sama sekali hak-hak istimewa orang Inggris di Thailand, antara lain orang Inggris bebas berdagang di Thailand. Hal tersebut dilakukan agar tidak menimbulkan kecemburuan Prancis sehingga dijadikan alasan menyerbu Thailand. Meskipun hak-hak istimewa Inggris itu sudah ditukar dengan Malaya, namun Inggris dan Prancis tetap menekan Thailand.

Tahun 1896 kedua bangsa Barat itu sepakat untuk menempatkan Thailand sebagai negara pemisah antara kekuasaan Inggris di Myanmar dan Prancis di Indocina. Dengan demikian kedua negara Barat itu sungguh-sungguh menghormati bahkan menjaga kedaulatan Thailand. Kehebatan politik diplomasi Thailand juga diperlihatkan pada masa berikutnya, sewaktu Jepang mulai mengancam Thailand, maka pada tahun 1898 raja Chulalongkorn mengadakan perjanjian dengan negeri matahari terbit itu. Sedangkan untuk menghindari bangsa Barat yang lain, maka dalam Perang Dunia I Thailand memihak Sekutu sehingga negeri itu benar-benar terhindar dari ancaman bangsa Barat.

Dalam rangka untuk mengimbangi kemajuan bangsa Barat maupun Jepang, Thailand melancarkan modernisasi di segala bidang, terutama politik dan militer. Tindakan yang pertama yaitu menghapus nama Siam (1939) yang biasa 
digunakan banyak negara untuk menyebut Thailand atau Muangthai. Adapun alasan penggantian nama tersebut karena Siam diartikan sebagai bangsa budak, sedangkan Muangthai berarti negerinya orang-orang bebas (Kusumohamidjojo, 1985: 50).

\section{Indonesia}

Elson (2009: 22-23) menjelaskan, yang memberi kekuatan kepada gagasan Indonesia bukanlah kesatuan yang dibangun atas solidaritas etnis atau ras, keterikatan keagamaan, atau bahkan kedekatan geografis, melainkan rasa kesamaan pengalaman dan solidaritas khusus yang mengalir darinya.

Sejarah membuktikan, nasionalisme politik Indonesia cukup mampu merajut kepentingan masyarakat plural yang sulit menemukan kehendak bersama. Akan tetapi, keampuhan nasionalisme politik ini baru teruji sebagai kekuatan nasionalisme negatif-defensif, ketika dihadapkan pada keburukan musuh bersama daru luar (penjajahan). Padahal, dengan berlalunya kolonial, proyek kebangsaan Indonesia yang berlandaskan pada penemuan "batas" dan "lawan" dengan kolonial itu bersifat kadaluwarsa (Latif, 2011: 366).

Indonesia sendiri dari sisi istilah baru ada pada abad ke- 19 lebih tepatnya pada 1850 ketika seorang pelancong dan pengamat sosial asal Inggris, George Samuel Winsor Earl menggunakan kata "Indu-nesians" (Elson, 2008:2) dalam tulisannya. Ini pun bukan berarti dengan sendirinya bangsa Indonesia terbentuk secara otomatis setelah nama Indonesia muncul. Semangat nasionalisme Indonesia dimulai justru ketika munculnya golongan terpelajar yang menyadari betapa pentingnya rasa identitas bersama sebagai landasan untuk melawan praktik kolonialisme dan imperialisme bangsa asing.

Lebih lanjut Yudi Latif (2011:358) memaparkan; bangsa Indonesia tidak seperti kebanyakan bangsa yang mengambil namanya dari kelompok etnik terdahulu: England dari Angles, Finland dari Finns, France dari Franks, Rusia dari Rus, Vietnam dari Viet, Thailand dari Thai, Malaysia dari Melayu, dan lain sebagainya. Ditinjau dari sudut ini, kesadaran kebangsaan Indonesia jelas bukanlah suatu perpanjangan dari kesadaran etno-kultural.

Fakta tersebut menjelaskan bahwa secara sadar Indonesia adalah negara yang disepakati akan melindungi dan menempatkan setiap suku, ras dan etnis yang terdapat didalamnya secara sejajar, tidak memihak etnis tertentu. Sikap nasionalisme yang dikembangkan para pendiri bangsa tersebut tentu saja diantaranya didasari oleh adanya persepsi positif terhadap keberagaman budaya bangsa. Para pendiri bangsa menyadari bahwa keberagaman yang ada telah menjadi kekuatan dalam perjuangan, terlebih pada masa revolusi.

Oleh karena itu, untuk mengerti sifat nasionalisme Indonesia dan gerakan revolusioner di mana isme itu berkembang, perlu diliki suatu pengetahuan tentang ciri-ciri terpenting dari lingkungan sosial yang melahirkannya. Lingkungan penjajahan abad keduapuluh yang menentukan tahap nasionalisme Indonesia modern yang jelas dan konkrit, adalah tahap yang menuntut analisis menyeluruh. Akan tetapi, analisis semacam itupun tidak akan memuaskan tanpa adanya pemahaman terlebih dahulu tetang proses historis sebelumnya dari pembentukan ciri-ciri lingkungan yang lebih menonjol (Kahin, 1995: 1).

Sehubungan dengan latar belakang sejarah nasionalisme Indonesia Sartono Kartodirjo (1998) menjelaskan, pertumbuhan negara-nasion dalam abad ke-19 bersamaan dengan perkembangan demokrasi, parlementarianisme dan konstitusionalisme, kesemuanya memantapkan pembangunan civil society. Sejarah perkembangan nasionalisme di dunia ketiga senantiasa sebagai counterideology kolonialisme, sebagai ideologi yang bertujuan memperjuangkan kebebasan untuk membangun negara nasion mencakup komunitas multi etnis sebagai kesatuan.

Sebagaimana halnya dengan kebanyakan negara baru yang berasal dari kancah perjuangan menentang kolonialisme lainnya, Indonesia tidak tumbuh dari perpecahan negara yang multi etnis. Secara simbolis dapat dikatakan bahwa kelahiran 
Indonesia sebagai bangsa dan negara adalah hasil perjuangan kaum nasionalis untuk menciptakan sebuah bangsa yang bisa menjawab tantangan zaman modern (Taufik Abdullah, 1998).

Adanya intervensi dari kekuatan luar telah menunjukkan bahwa kekuatan nasionalisme sebagai ideologi yang disepakati menjadi penting untuk membawa bangsa menuju kemerdekaan (Hobsbawm, 1990). Dengan demikian jelas bahwa nasionalisme Indonesia merupakan nasionalisme yang terbentuk melalui suatu proses perjuangan dan kesadaran. Bukan merupakan nasionalisme yang tumbuh secara alami karena persamaan ras, suku, atau bahasa, akan tetapi nasionalisme yang muncul karena adanya persamaan nasib dan sekaligus merupakan jawaban atas keinginan memecah belah dan menguasai yang dilakukan oleh bangsa asing.

Gerakan nasional di Indonesia dimulai dengan berdirinya Budi Utomo pada tahun 1908, yang sekaligus menandai lahirnya nasionalisme Indonesia yang pertama. Wadah kaum nasionalis yang pertama ini dalam perkembangannya mengalami pasang surut. Hal ini dapat kita lihat peristiwa keluarnya tokoh-tokoh radikal seperti $\mathrm{dr}$ Cipto Mangunkusumo dan Suwardi Suryaningrat dari organisasi tersebut setelah Pangeran Notoprojo dari Pakualaman memegang pimpinan pada tahun 1911(Niel, 1984: 94). Meskipun demikian dalam perkembangan sejarah, para sejarawan mengkritik jika organisasi ini dijadikan tonggak awal gerakan nasional Indonesia karena sifatnya yang sangat eksklusif ke-Jawa-an.

Berikutnya tercatat Sarekat Islam yang moderat tetapi akhirnya menjadi radikal setelah kemasukkan Marxisme dan menjadi oposisi pemerintah (1916), dengan anggota sekitar 960 ribu orang, Sarekat Islam itu menuntut pemerintahan sendiri dan pada tahun 1919 dengan jumlah anggota 2,5 juta orang telah mencantumkan program kemerdekaan penuh (Kahin, 1995). Selama antara setahun sampai dua tahun ada semacam kerjasama tertentu antara Sarekat Islam dan Partai Komunis (PKI). PKI itu berdiri pada tanggal 23 Mei 1920, dan partai inilah yang melakukan infiltrasi ke dalam tubuh Sareka Islam. Sebagai akibat infiltrasi komunis itu, maka akhirnya terjadi perbedaan pendapat yang memecah Sarekat Islam pada tahun 1921. Usaha ketua Sarekat Islam (Cokroaminoto) untuk mengembalikan Sarekat Islam gagal total (Utrecht, 1984: 31).

Setelah gerakan nasional yang berdasarkan Islam dan komunis mengendor, maka muncullah gerakan nasional yang lebih nasionalistis. Dalam tahun 1927 Soekarno mendirikan PNI yang berkarakteristik agitasi kuat dan sikap nonkooperatif terhadap pemerintah Belanda. Akhirnya Belanda tidak menerima kegiatan semacam itu, karena itu PNI kemudian dibubarkan dan para pemimpinnya ditahan (Moedjanto, 1988: 59-60). Penahanan tersebut tidak mengakhiri perjuangan nasionalisme Indonesia, berbagai organisasi dan gerakan-gerakan kelompok yang bercita-cita Indonesia merdeka terus berkembang meskipun banyak di antara tokoh mereka harus menerima nasib seperti Soekarno.

Pada masa perang dunia II perjuangan nasionalisme Indonesia terus berlangsung, bahkan pada masa pendudukan Jepang perjuangan tersebut semakin terstruktur. Para pemimpin pergerakan seolah-olah mau bekerjasama dengan Jepang, namun mereka menggunakan organisasi-organisasi yang didirikan Jepang untuk melanjutkan perjuangan mencapai kemerdekaan. Setelah Jepang menyerah kepada Sekutu (14 Agustus 1945), para pemimpin pergerakan nasional mempersiapkan kemerdekaan, dan pada tanggal 17 Agustus 1945 kemerdekaan Indonesia diproklamirkan.

\section{PENUTUP}

Tipe nasionalisme secara tradisional dapat dibagi menjadi dua yakni civic nationalism dan ethnic nationalism (Barrington, t.t.). Dalam ethnic nationalism, bangsa didefinisikan dalam hal etnis dan keturunan dari generasi sebelumnya. Hal ini juga mencakup gagasan budaya bersama antara anggota kelompok, dan biasanya juga mencakup 
bahasa yang sama. Sedangkan, civic nationalism adalah bentuk nasionalisme yang berasal dari legitimasi politik dari keikutsertaan aktif masyarakat, yang mana hal tersebut merupakan "will of the people" (Kelas, 1998). Contoh dari civic nationalism ini diantaranya adalah gerakan nasional Indonesia. Negara-negara di kawasan Asia Tenggara bila diteliti mengalami kedua proses ini. Ethnic nationalism misalnya ditunjukkan oleh Thailand, sedangkan civic nationalism misalnya ditunjukkan oleh Philipina dan Indonesia. Dalam tinjauan ini Malaysia dapat dikatakan mengalami kedua tipe identifikasi ini, ditengah upaya mengukuhkan identitas ke-Melayu-an, Malaysia juga harus mampu mengakoomodir keinginan warga negara lain non Melayu. Meskipun demikian, bila dilihat dari sisi identitas nasional nation state, maka Indonesia dapat dikatakan satu-satunya negara di Asia Tenggara yang secara tegas menggunakan terminologi multikultural dalam penamaan negara. Ditinjau dari sejarah kawasan sangat jelas bahwa nasionalisme Indonesia tidak dibangun atas dasar etno-kultural, akan tetapi keinginan bersama yang dalam pandangan Barington tersebut merupakan civic nationalism yang murni.

Nasionalisme yang hadir di Asia Tenggara yang menurut Chong (2009) juga dipengaruhi oleh tiga faktor yakni agama, pendidikan Barat, radical social dan komunisme. Faktor terakhir yakni komunisme menjadi faktor paling dominan dalam pembentukan nasionalisme di Asia Tenggara, hal ini didukung fakta bahwa nasionalisme muncul sebagai respon terhadap pemerintahan yang buruk di bawah kolonialisme dengan perlakuan eksploitatif dan penindasan oleh para penjajah. Dalam kasus Indonesia tidak dapat dilepaskan peran besar Islamisme dalam sejarah pergerakan nasional. Vietnam dan Filipina adalah negara yang lebih dulu merasakan signifikansi dari nasionalisme. Rasa nasionalisme ini kemudian menimbulkan berbagai signifikansi terhadap perubahan nasib bangsa yang terjajah tersebut. Pengalaman kolonial berdampak pada munculnya anti-kolonial serta anti-fasis yang memiliki semangat nasionalis dengan menelurkan gerakan kemerdekaan. Agama memainkan peran penting dalam masyarakat Asia Tenggara. Agama dikombinasikan dengan kesadaran budaya, menghasilkan bentuk kesadaran nasional yang khas. Dalam konteks regional tidak dapat diingkari pula bahwa nasionalisme di kawasan Asia Tenggara terjadi di tengah kemampuan mengkombinasikan semangat anti kolonialisme dengan kemampuan menyerap ide-ide/pemikiran modern tentang cita-cita bersama sebagai bangsa yang merdeka.

\section{DAFTAR PUSTAKA}

Abdullah, T. 1998. "Dinamika Regionalisme dalam Konteks Negara Nasional", dalam Regionalisme, Nasionalisme, dan Ketahanan Nasional. Jogjakarta: UGM Press.

Anderson, B. 2001. Imagined Communities. Jogjakarta: Insist.

Barrington, L. W. t.t. Nationalism and Independence. The university of Michigan press.

Chong,T. 2009. "Nationalism in Southeast Asia: Revisiting Kahin, Roff, and Anderson". Journal of Social Issues in Southeast Asia,Vol.24, No.1, pp 117.

Diamond, dkk. 1998. Nasionalisme, Konflik Etnis, dan Demokrasi. Bandung: Penerbit ITB.

Donnison, F.S.V., 1970. Burma, London: Ernest Benn Limited

Edi S. 1998. "Regionalisme, Nasionalisme, dan Ketahanan Nasional: Satu Tinjauan dari Segi Strategi Hankam", dalam Regionalisme, Nasionalisme, dan Ketahanan Nasional. Jogjakarta: UGM Press.

Elson, R.E. 2008. The Idea of Indonesia, Sejarah Pemikiran dan Gagasan. Jakarta: Serambi Ilmu Semesta. 
Emerson, R. 1946. "An Analysis of Nationalism in Southeast Asia". The Far Eastern Quarterly,Vol. 5, No.2, pp 208-215.

Hobsbawm, E.J. 1990. Nations and Nationalism Since 1780: Programme, Myth, Reality. Cambridge: Cambridge University Press.

Kahin, G. 1995. Refleksi Pergumulan Lahirnya Repiblik, Nasionalisme dan Revolusi di Indonesia. Surakarta: UNS Press dan Pustaka Sinar Harapan.

Karnaw, S. 1975. Vietnam a History, New York: The Niking Press

Kartodirdjo, S. 1998. "Kesukuan dan Masyarakat Adab", dalam Regionalisme, Nasionalisme, dan Ketahanan Nasional. Jogjakarta: UGM Press.

Kellas, J. G. 1998. The politics of nationalism and ethnicity. New York: st martin press.

King, Victor T. \& Wilder, William D. 2012. Antropologi Modern Asia Tenggara, Sebuah Pengantar. Yogyakarta: Kreasi Wacana.

Koen, A. Peng. 1956. Perang Pasifik 1941-1945, Jakarta: Keng Po

Kusumohamidjojo, B. 1985. Asia Tenggara dalam Perspektif Netralitas dan $\mathrm{Ne}$ tralisme, Jakarta: PT. Gramedia

Latif, Y. 2011. Negara Peripurna: Historisitas, Rasionalitas, dan Aktualitas Pancasila. Jakarta: Gramedia Pustaka Utama.

Leightfoot, K. 1973. The Philippines, London: Ernest Benn limited

Moedjanto, G. 1988. Indonesia Abad ke-20, jilid I, Cetakan I. Yogyakarta: Penerbit Kanisius

Nagata, J. 1979. Malaysian Mosaic: Perspectives from a Poly-Ethnic Society. Vancouver: University of British Columbia Press.

Niel, R. 1984. Munculnya Elite Modern Indonesia (terjemahan), Jakarta: Pustaka Jaya
Perdanayudha. 2010. Sikap Nasionalisme Bagi Manusia. dalam http://perdanayudha.wordpress.co m/2010/05/27/sikapnasionalisme-bagi-manusia/ (diakses Kamis 15 September 2011)

Plamenatz, J. 1973 "Two Types of Nationalism," in Eugene Kamenka (ed.),Nationalism, The Nature and Evolution of an Idea. Canberra: ANU Press.

Sardiman AM, 1983. Kemenangan Komunis Vietnam dan Pengaruhnya Terhadap Perkembangan Politik di Asia Tenggara, Yogyakarta: Liberty.

Suryo, D. 2003. "Pendidikan Sebagai Upaya Membangun Sikap Kebangsaan Melalui Nilai-nilai Pluralitas Budaya Bangsa", Historika Volum 1, No. 1, Juli 2003. Surakarta: Program Pascasarjana Pendidikan Sejarah Universitas Sebelas Maret.

Utrecht, E. 1984. The Muslim Merchant Class in Indonesia, Belgia: Sosial Compass $\mathrm{XXXI} / 1$

Wirosarjono, S. 1998. "Budaya Daerah dan Ketahanan Nasional" dalam Regionalisme, Nasionalisme, dan Ketahanan Nasional. Jogjakarta: UGM Press.

Wiyono, 1982. Sejarah Asia Tenggara Modern, Yogyakarta: Jur.Pensej, IKIP Sanata Dharma 